\title{
Hydrogen and Methane Production from Styrofoam Waste Using an Atmospheric-pressure Microwave Plasma Reactor
}

\author{
Raynard Christianson Sanito ${ }^{1,2}$, Ya-Wen Chen², Sheng-Jie You ${ }^{2,3,4}$, Hsi-Hsien Yang ${ }^{5}$, \\ Yen-Kung Hsieh ${ }^{6}$, Ya-Fen Wang ${ }^{2,3,4^{*}}$
}

${ }^{1}$ Department of Civil Engineering, Chung Yuan Christian University, Taoyuan 32023, Taiwan

${ }^{2}$ Department of Environmental Engineering, Chung Yuan Christian University, Taoyuan 32023, Taiwan

${ }^{3} R \&$ D Centre for Membrane Technology, Chung Yuan Christian University, Taoyuan 32023, Taiwan

${ }^{4}$ Center for Environmental Risk Management, Chung Yuan Christian University, Taoyuan 32023, Taiwan

${ }^{5}$ Department of Environmental Engineering and Management, Chaoyang University of Technology, Taichung 413310,

Taiwan

${ }^{6}$ Marine Ecology and Conservation Research Center, National Academy of Marine Research, Kaohsiung 80661, Taiwan

\begin{abstract}
Polystyrene foam (PSF), which is widely used in oyster farming in Taiwan, generates approximately 120,000-200,000 pieces of floating waste annually. The issues related to processing this waste, however, include the financial cost, incinerator clogs, human exposure to carcinogenic and non-biodegradable components, and potential debris, which threatens the seashore. In this study, we obtained methane $\left(\mathrm{CH}_{4}\right)$ and hydrogen $\left(\mathrm{H}_{2}\right)$, two crucial gases in power generation, by treating PSF waste with an atmospheric-pressure microwave plasma reactor. Substituting argon with nitrogen as the carrier gas and increasing the microwave power $(1200 \mathrm{~W})$ produced a higher concentration of $\mathrm{H}_{2}(4739 \mathrm{ppm})$ but a lower one of $\mathrm{CH}_{4}(\mathrm{less}$ than $300 \mathrm{ppm})$. Treating a larger quantity of waste $(0.2 \mathrm{~g})$ resulted in $\mathrm{CH}_{4}$ and $\mathrm{H}_{2}$ levels of 19,657 ppm and $440 \mathrm{ppm}$, respectively. SEM-EDX and XRD testing confirmed the transformation of the PSF structure and a reduction in carbon (C) content in the final residue. This research demonstrates how solid waste can be recycled into valuable gases by applying plasma technology.
\end{abstract}

Keywords: $\mathrm{CH}_{4} ; \mathrm{H}_{2}$; Microwave power; Nitrogen; PSF.

\section{INTRODUCTION}

Plastic debris has a significant impact in various sectors of society, including beaches, biodiversity, tourism, ecosystems, and human health (Pomeroy and Guieb, 2006; Liang and Zhang, 2010; Allen et al., 2013; Tanaka, 2013; UNEP, 2013; Hong et al., 2014; Lee et al., 2015; Lee et al., 2017; Vince and Hardesty, 2018). Styrofoam, which is made from a polystyrene foam (PSF), is a type of plastic debris, and that is quite difficult to degrade naturally (Chen et al., 2018). According to Tanaka et al. (2013), the transferring of chemical pollutants from marine environments to marine organisms occurs through the food chain, and is harmful to the ecosystem, and also to organism itself. Accumulation of plastic debris in animals, for examples, birds, occurs because of accidental ingestion, and was reported in 171 birds from 9 species by

\footnotetext{
* Corresponding author.

Tel.: +886-3-2654912; Fax: +886-3-2654949

E-mail address: yfwang@cycu.edu.tw
}

Codina-Garcia et al. (2013). Provencher et al. (2010) and Holland et al. (2016) confirmed that plastic debris is ingested by diving seabirds in eastern Canadian Arctic and affects their health. Thereby, plastic waste is harmful to organisms and environments.

In several countries, PSF waste has become a serious environmental issue that should be managed properly because of the large amount that has contaminated the environment. Laglbauer et al. (2016) found that macro-debris in the ocean in Slovenia is comprised of as much as $64 \%$ plastics. Fujieda and Sasaki (2005) discovered that $99.5 \%$ of foamed plastic fragments can be found along approximately $48.6 \mathrm{~km}$ of Japan's coastline. A finding of Lee et al. (2015) stated that $1,800,000$ buoys contaminate ocean annually in the South Korean sea. In Taiwan, between 3.7 million and 7.9 million approximately of plastic debris in the form of shopping bags, plastic bottle caps, tableware, fishing equipment, and plastic drinking straws, contaminated the coastline of Taiwan from 2004 to 2016 (Walther et al., 2016). Chen et al. (2018) reported that in Taiwan, approximately 120,000-200,000 large floating pieces of Styrofoam used for oyster farming every year. Polystyrene foam has been used widely in oyster 
farming and has become a main issue because of their shorter lifetime of approximately three years, and it is difficult to recycle (Liu et al., 2013; Chen et al., 2018). Thus, contamination with plastic waste is a serious issue, and should be handled correctly to prevent environmental pollution.

Several technologies have been developed to deal with plastic waste, namely, incineration (Ganeshprased, 2002; Choi et al., 2008; Wang et al., 2018, Yang et al., 2019) and recycling (Xu et al., 2013). Unfortunately, there are some drawbacks to both incineration and recycling. Unstable combustion, lack of air pollution control, high concentrations of dioxin, halogenated polycyclic hydrocarbons, and remaining pathogens are disadvantages of incineration (Nema and Ganeshprasad, 2002; Choi et al., 2008; Wang et al., 2018; Yang et al., 2019), as well as limited energy recovery and heavy water consumption (European Commission, 2006). $\mathrm{Xu}$ et al. (2013) reported that the recycling areas are contaminated by tetrachlorodibenzo- $p$-dioxins (TCDDs) and octachlorodibenzo- $p$-dioxin (OCDD) from melting plastic of e-waste. The total concentrations of TCDDs to OCDD were $2816-17,738 \mathrm{pg} \mathrm{g}^{-1}$ in soil. Thus, proper technology is required to tackle these issues.

Investigations of plasma technology in environmental application to treat waste have been performed by several authors (Heberlein and Murphy, 2008; Gomez et al., 2009; Deng et al., 2019; Sanito et al., 2020). Transformation of electrical energy to thermal energy occurs because of the invention of an electrical arc between two electrodes; subsequently, ionization occurs, which leads to the conversion of gas to electrically conductive compounds for elimination of elements (Taylor and Pirzada, 1994; Chang, 2009). Heberlein and Murphy (2008) and Wang et al. (2010) stated that the benefits of plasma technology include start-up of the reactor and plants, variety of chemical processes, low gas flow rate, high electron density, straightforward operation procedure, and easier application of recycling products in manufacturing processes. Thereby, plasma technology is a prospective technology to treat waste.

Previous studies have stated that in term of plasma technology, hydrogen $\left(\mathrm{H}_{2}\right)$ and methane $\left(\mathrm{CH}_{4}\right)$ can be generated from biomass and plastic waste (Huang et al., 2003; Chu et al., 2006; Mazzoni and Janajreh, 2007; Dave and Joshi, 2010; Mackzka, 2013; Tang et al., 2013; Shie et al., 2014; Materazzi et al., 2015; Huang et al., 2016; Sanlisoy and Carpinlioglu, 2017). Huang et al. (2013) found that the main components of the gaseous products from waste rubber were $\mathrm{CO}, \mathrm{C}_{2} \mathrm{H}_{2}, \mathrm{CH}_{4}, \mathrm{C}_{2} \mathrm{H}_{4}$ and $\mathrm{H}_{2}$. Materazzi et al. (2015) reported that the final products, $\mathrm{CO}, \mathrm{H}_{2}$ and $\mathrm{H}_{2} \mathrm{~S}$, can be obtained from tar under plasma gasification, which reduced complex organics by more than $96 \% \mathrm{v} / \mathrm{v}$. In the treatment of paper mill waste, approximately $90 \%$ of $\mathrm{CO}$ and $99 \%$ of $\mathrm{H}_{2}$ can be obtained with a 2 min reaction time in a Plasmatron reactor, and 1.2 tons of paper mill waste can be recovered per day (Byun et al., 2011; Shie et al., 2014). Therefore, plasma technology is a promising procedure for treatment of solid waste and gasification of materials.

Previous researchers have reported on how to handle the plastic waste and produces synthetic gas ("syngas") through plasma pyrolysis (Ruj and Chang, 2003; Dave and Joshi,
2010; Maczka et al., 2013; Zhou et al., 2020). Tang et al. (2003) reported that $\mathrm{H}_{2}$ gas can be produced from polypropylene in a nitrogen plasma reactor in a DC arc nitrogen plasma generator, with a maximum electric power input of $62.5 \mathrm{kVA}$ in a $50 \mathrm{~mm}$ reaction chamber. Dave and Joshi (2010) found that the integration of thermo-chemical properties of plasma generates pyrolysis gas from polyethylene $(\mathrm{PE})$, and polypropylene (PP) at temperatures ranging from $800-1000^{\circ} \mathrm{C}$ and can be considered on energy recovery with $78 \%$ propylene, and $\mathrm{CO}, \mathrm{H}_{2}$, and hydrocarbons can be successfully recovered. $\mathrm{NO}_{x}$ and $\mathrm{H}_{2} \mathrm{~S}$, which are toxic gases, can be eliminated during plasma pyrolysis (Ruj and Chang, 2002). Maczka et al. (2013) discovered that plasma pyrolysis of waste plastics produces $\mathrm{H}_{2}, \mathrm{CH}_{4}$, and $\mathrm{CO}$ with values of $1.1 \%, 2 \%$, and $0.3 \%$, respectively. Zhou et al. (2020) found that industrial atmospheric dielectric-barrier-discharge plasma can be used to treat plastic bags using a mechanism that breaks the chemical bonds of the plastic bag. Therefore, plasma technology can be used to produce a syngas from plastic waste. However, the treatment of PSF waste in plasma technology for such applications has not been thoroughly investigated or successfully performed.

In this study, potential hydrogen $\left(\mathrm{H}_{2}\right)$ and methane $\left(\mathrm{CH}_{4}\right)$ production as a side product in an atmospheric-pressure microwave plasma reactor is investigated. Furthermore, the composition of organic compounds is analyzed. To the author's knowledge, PSF waste has not yet been discussed in any scientific literature, especially in terms of treatment using an atmospheric-pressure microwave plasma reactor. This paper is a study of the use of atmospheric-pressure microwave plasma to produce gas as a side product derived from PSF waste. In this study, the effects of carrier gases and microwave power on the total concentration of $\mathrm{H}_{2}$ and $\mathrm{CH}_{4}$ are then presented to understand the gas production mechanism.

\section{METHODS}

\section{Collection and Preparation of the Samples}

PSF waste was collected from an oyster farm in Tainan, Taiwan. The PSF waste product measured $30 \times 40 \times 95 \mathrm{~cm}$. The sample was cut into smaller pieces $(1 \mathrm{~cm})$ and was measured with a standard analytical balance (AUY-220; Shimadzu, Japan) before being used in the experiment.

\section{Pyrolysis of PSF Waste}

Fig. 1 describes the atmospheric-pressure microwave plasma reactor. In this experiment, an atmospheric-pressure microwave plasma reactor was used with a frequency ranging between $0.3 \mathrm{GHz}$ and $10 \mathrm{GHz}$, and the slurry frequency was set at $2.45 \mathrm{GHz}$ (wavelength: $12.2 \mathrm{~cm}$ ). An $\mathrm{MCw}$ signal was generated by a magnetron through a waveguide. Pyrolysis of the PSF waste was performed in a $20 \mathrm{~cm}^{3}$ crucible, for which height and diameter were $4 \mathrm{~cm}$ and $2.5 \mathrm{~cm}$, respectively. A $0.1-\mathrm{cm}$-thick quartz tube with a diameter of $3 \mathrm{~cm}$ and a length of $32 \mathrm{~cm}$ was positioned near the path of magnetron propagate where plasma jet discharged.

Fig. 2 illustrates the preparation of the sample and treatment in an atmospheric-pressure microwave plasma 


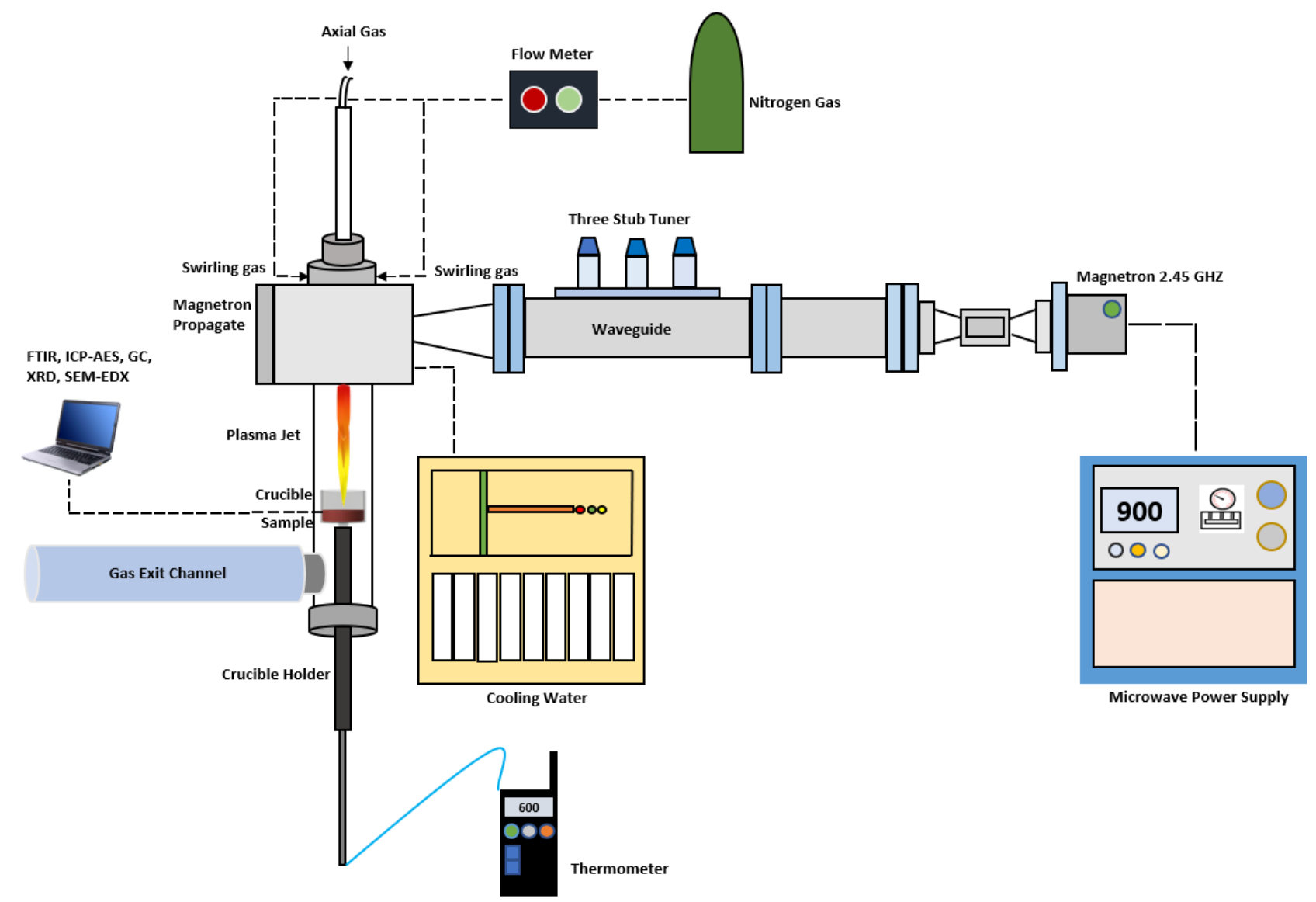

Fig. 1. The system of an atmospheric-pressure microwave plasma reactor in this study.

a

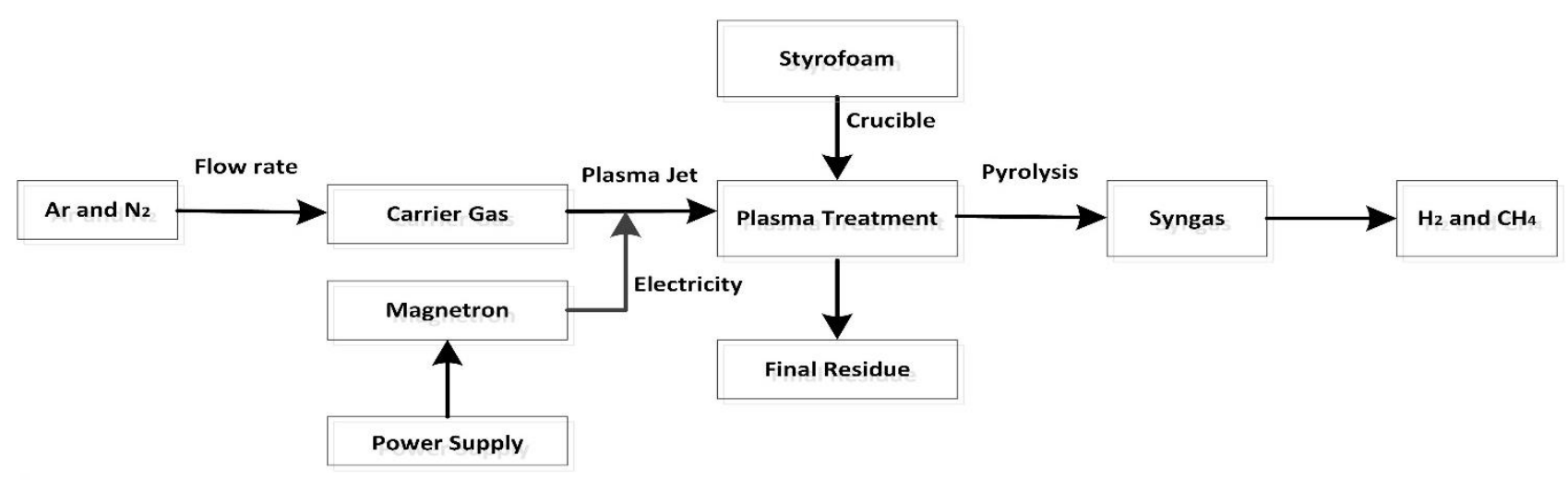

b

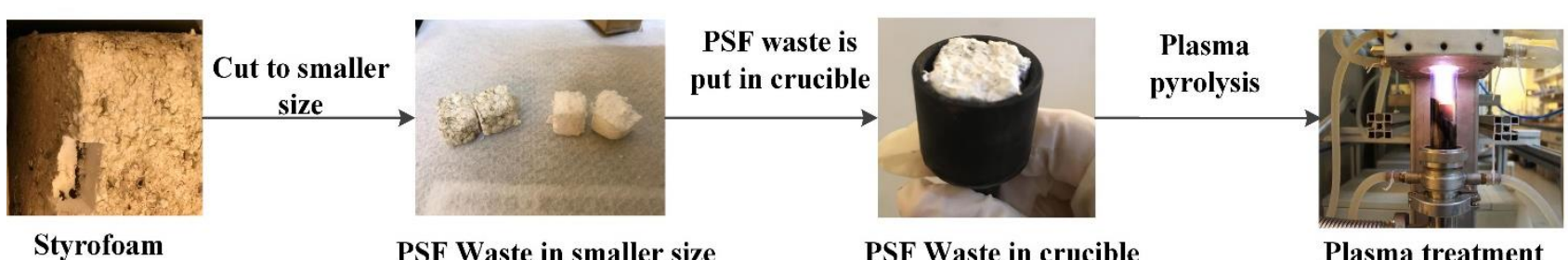
(PSF waste)

Fig. 2. Setup of plasma treatment and preparation. (a). Schematic set up of plasma treatment. (b). PSF treatment in an atmospheric-pressure microwave plasma reactor. 
reactor. Fig. 2(a) shows a schematic of the plasma treatment set-up. Approximately $0.1 \mathrm{~g}$ of PSF waste was used as the sample. Fig. 2(b) shows how the waste prepared and treated in atmospheric-pressure microwave plasma reactor. To generate a plasma jet, the microwave power was kept constant at $1000 \mathrm{~W}$. Argon gas and nitrogen gas were used as the carrier gases to generate the plasma jet for $4 \mathrm{~min}$ with $0.1 \mathrm{~g}$ of PSF waste. The parameters of the experiment are explained in Table 1.

To investigate the effects of microwave power on the treatment, different amounts of power were utilized. The plasma power was maintained at $800 \mathrm{~W}$ and $1200 \mathrm{~W}$, respectively. The plasma jet was discharged through a magnetron, and gases were collected via a $1 \mathrm{~L}$ gas bag (Tedlar gas bags) each 30 seconds. Plasma pyrolysis was performed at 4 min using nitrogen as the carrier gas (fast reaction and high metastable energy), while argon gas is used with 5 min of pyrolysis. The details of this process are shown in Table 2.

To assess the effects of the amount of PSF waste on production of $\mathrm{H}_{2}$ and $\mathrm{CH}_{4}, 0.1 \mathrm{~g}, 0.2 \mathrm{~g}$, and $0.3 \mathrm{~g}$ of PSF waste were used as the samples treated in the atmosphericpressure microwave plasma reactor. The microwave power was maintained at $1000 \mathrm{~W}$; nitrogen was used as the carrier gas, and pyrolysis was performed at $4 \mathrm{~min}$. The experiment is displayed in Table 3. In this study, the liquid product and mass balance were not determined because of their small quantities in the final residue after treatment.

\section{Gas Analysis}

$\mathrm{CH}_{4}$ and $\mathrm{H}_{2}$ gases in the samples were analyzed via gas chromatography (GC-14A/B and GC-2014; Shimadzu, Japan). The lock syringe size of $1 \mathrm{~mL}$ (Taiwan) was used to inject the gas. A thermal conductivity detector (TCD) and flame ionization detector (FID) were used to detect the $\mathrm{H}_{2}$ and $\mathrm{CH}_{4}$, respectively. The columns were Porapak Q 80/100 mesh and a molecular sieve (5A Column). Standard carrier gases $\left(\mathrm{CH}_{4}\right.$ and $\left.\mathrm{H}_{2}\right)$ were purchased from the Ming Yang Company (Taiwan). The flow rate was set up at $30 \mathrm{~mL} \mathrm{~min}^{-1}$ and maintained isothermally at $120^{\circ} \mathrm{C}$. Concentrations of $\mathrm{CH}_{4}$ gas standard were $100 \mathrm{ppm}, 200 \mathrm{ppm}, 400 \mathrm{ppm}$, and $800 \mathrm{ppm}$, and concentrations of $\mathrm{H}_{2}$ gas were $100 \mathrm{ppm}$, $200 \mathrm{ppm}$, and $400 \mathrm{ppm}$. In this study, only analyses of $\mathrm{H}_{2}$ and $\mathrm{CH}_{4}$ were considered

\section{Analysis of Sample Properties}

Scanning electron microscopy (SEM-EDX; S-4800; Hitachi, Japan) was used to analyze the surface morphology of the PSF. The results of this analysis provided the surface and morphological structure of the residue.

To analyze the functional groups available in the PSF before and after treatment, Fourier transform infrared spectroscopy (FTIR; FT/IR-6000; Jasco, USA) was used with wavenumbers ranging from $400-4000 \mathrm{~cm}^{-1}$. The PSF was pelleted with $\mathrm{KBr}$, and samples were pressed using a manual hand press until samples were $1 \mathrm{~mm}$ in size. After that, the samples were placed in the FTIR instrument and scanned with infrared rays for 5 min. FTIR curves were determined using Origin software (version 9.1).

To analyze the characteristics and crystalline structures of the resin, X-ray diffraction (XRD; D8 Advance Eco; Bruker, Germany) was used. The scanning process was performed for 5 min using $X$-rays with $2 \theta$ scanning at a range $10-80^{\circ}$. The X-rays were performed using asymmetric diffraction from the modular components. The voltage was controlled at $40 \mathrm{kV}$, and the current was set up at $25 \mathrm{~mA}$. The power was maintained at $1000 \mathrm{~W}$, and $2 \theta$ peaks represented the PSF waste.

\section{RESULTS AND DISCUSSION}

\section{Characterization Analysis of PSF}

The surface morphology and elemental composition of the samples were determined using a scanning electron microscope

Table 1. Effect of sample weight on gas production rate of $\mathrm{CH}_{4}$ and $\mathrm{H}_{2}$.

\begin{tabular}{lllll}
\hline No & Carrier Gas & Microwave Power $(\mathrm{W})$ & Duration $(\mathrm{min})$ & Weight of PSF (g) \\
\hline 1 & Nitrogen & 1000 & 4 & 0.1 \\
2 & Argon & & & \\
\hline
\end{tabular}

Table 2. Effect of sample weight on gas production rate of $\mathrm{CH}_{4}$ and $\mathrm{H}_{2}$.

\begin{tabular}{llllll}
\hline No & $\begin{array}{l}\text { Microwave Power } \\
(\text { Watt })\end{array}$ & $\begin{array}{l}\text { Total Reaction Time } \\
(\text { Min })\end{array}$ & Carrier Gases & $\begin{array}{l}\text { Capturing of the gas } \\
(\text { Second })\end{array}$ & $\begin{array}{l}\text { Gas Flow } \\
\left.(\mathrm{L} \mathrm{min})^{-1}\right)\end{array}$ \\
\hline 1 & 800 & 4 & Nitrogen & $30,60,90,120$, & 6 \\
2 & 1200 & & & $150,180,210$, & \\
3 & 800 & 5 & Argon & $240,270,300$ & \\
4 & 1200 & & & & \\
\hline
\end{tabular}

Table 3. Effect of sample weight on gas production rate of $\mathrm{CH}_{4}$ and $\mathrm{H}_{2}$.

\begin{tabular}{lll}
\hline No & Parameters & Details Information \\
\hline 1 & Microwave power & $1000 \mathrm{~W}$ \\
2 & Duration & $4 \mathrm{Min}$ \\
3 & Weight of samples & $0.1 \mathrm{~g}, 0.2 \mathrm{~g}, 0.3 \mathrm{~g}$ \\
\hline
\end{tabular}


with energy-dispersive X-ray spectroscopy (SEM-EDX; Hitachi S-4800, Japan). Fig. 3 provides information about the surface morphology of the PSF samples before treatment and after treatment. Fig. 3(a) explains the regular morphological structure of Styrofoam, which is comprised of a chain of hydrogen and carbon. Fig. 3(b) shows the breakage surface of the materials after treatment with an argon plasma, which was found to assume a typical shape after treatment. Fig. 3(c) displays the irregular, inhomogeneous surface of the materials after treatment using nitrogen plasma, indicating destruction of the materials. Farrelly and Shaw (2017) confirmed that Styrofoam consists of vinyl benzene. In this study, carbon in the form of vinyl benzene was detected in the PSF waste before treatment. Material transformation refers to the degradation of linkages between materials and elements inpyrolysis process (Benedikt, 2010) because of free electrons at high concentrations that establish electrical conductivity from the carrier gas (Safa and Soucy, 2014). Specifically, ionization from the gas creates the collision of atoms, and enthalpy from the plasma produce the gases (Mountouris et al., 2006).

Fig. 4 explains the carbon composition before and after treatment. Fig. 4(a) gives an information about carbon in the PSF waste before treatment. Fig. 4(b) provides the carbon distribution after treatment in nitrogen plasma, and Fig. 4(c) depicts information about the PSF waste after treatment. All of this information shows that, based on the final residue after the plasma treatment, carbon was degraded better using the treatment. Lower concentrations of carbon could be obtained after treatment with nitrogen plasma because the high thermal degradation of the material plasma pyrolysis broke carbon bonds (Yang and Shibasaki, 1998).

Fig. 5 illustrates the FTIR patterns of the PSF waste after treatment in an atmospheric-pressure microwave plasma reactor. A qualitative analysis of functional groups was carried out to determine charactristics in the residue ranging from $400-4000 \mathrm{~cm}^{-1}$ of wavenumbers (Table 4). The analysis shows that $\mathrm{C}-\mathrm{H}$ and $\mathrm{C}-\mathrm{C}$ stretching vibration could be detected at $1493 \mathrm{~cm}^{-1}$ and $1601 \mathrm{~cm}^{-1}$, respectively. This finding was confirmed by Song et al. (2015), who stated that $721 \mathrm{~cm}^{-1}$, $1378 \mathrm{~cm}^{-1}, 2825 \mathrm{~cm}^{-1}$ and $2923 \mathrm{~cm}^{-1}$ wavenumbers represent $\mathrm{C}-\mathrm{H}$ groups. $\mathrm{C}-\mathrm{H}$ aliphatic and $\mathrm{C}-\mathrm{H}$ aromatic compounds, respectively, can be detected at wavenumbers ranging from 2910-2928 $\mathrm{cm}^{-1}$ and 3001-3082 $\mathrm{cm}^{-1}$ because of the presence of carbon. In the present, conversion of PSF waste to smaller components was due to the degradation of hydrocarbon and chemical bonds. There was a significant conversion of residue from the broadband peaks between $500 \mathrm{~cm}^{-1}$ and $1600 \mathrm{~cm}^{-1}$.

PSF waste materials after treatment using an argon plasma jet were found at wavenumbers of $1601 \mathrm{~cm}^{-1}, 1493 \mathrm{~cm}^{-1}$, 2910-2928 $\mathrm{cm}^{-1}$ and 3001-3082 $\mathrm{cm}^{-1}$. However, the peaks became smaller at $3200 \mathrm{~cm}^{-1}$. This indicates the transformation of these materials during the plasma treatment. A wavenumber at $3500 \mathrm{~cm}^{-1}$ was attributed to hydroxyl groups ( $-\mathrm{OH})$. This functional group relates to $\mathrm{C}=\mathrm{C}$ double bonds,

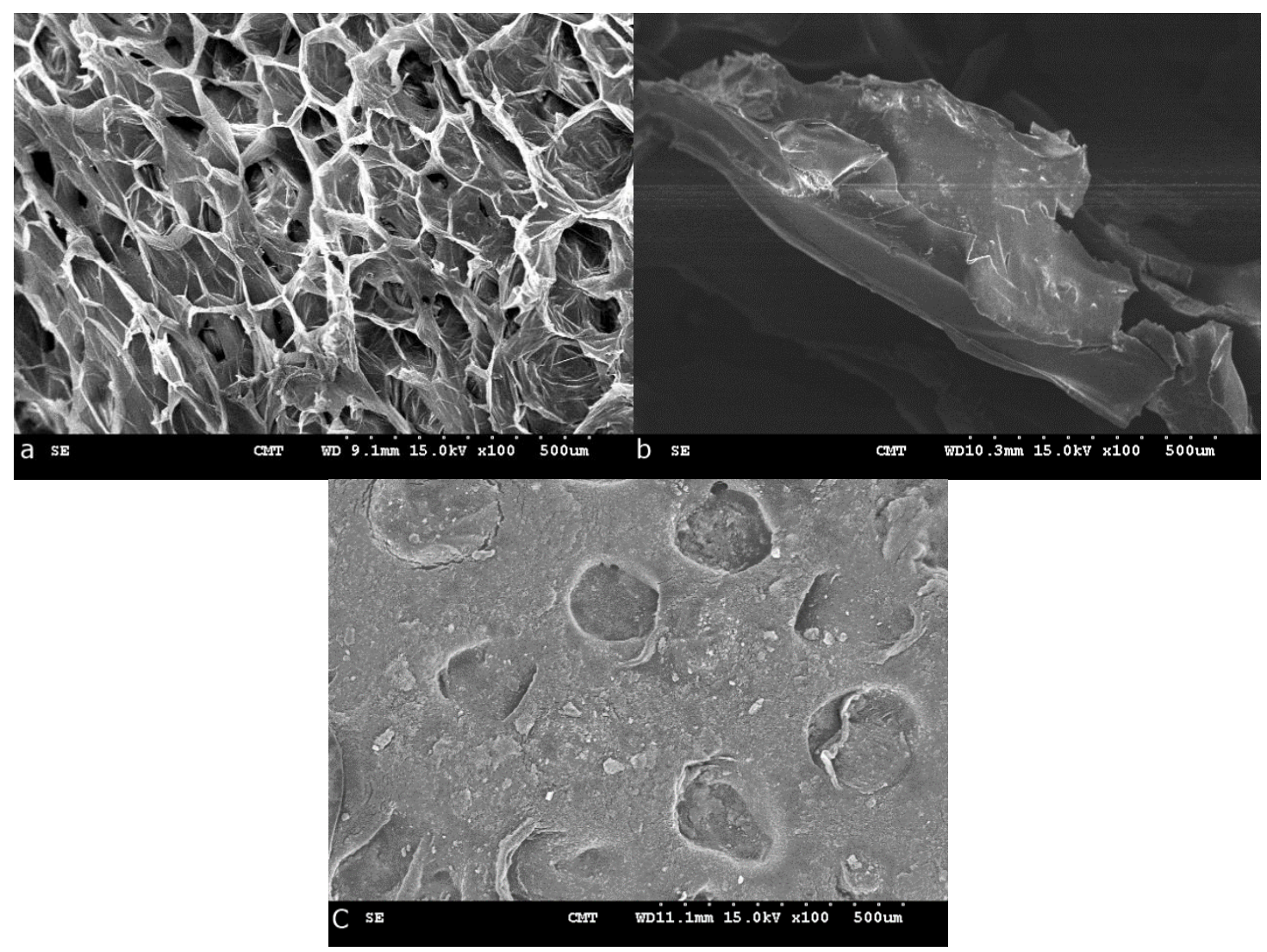

Fig. 3. SEM images of materials surface of Styrofoam. (a) Materials of Styrofoam before treatment. (b) Surface material of Styrofoam after treatment with argon gas. (c) Surface material of Styrofoam after treatment with nitrogen gas. 


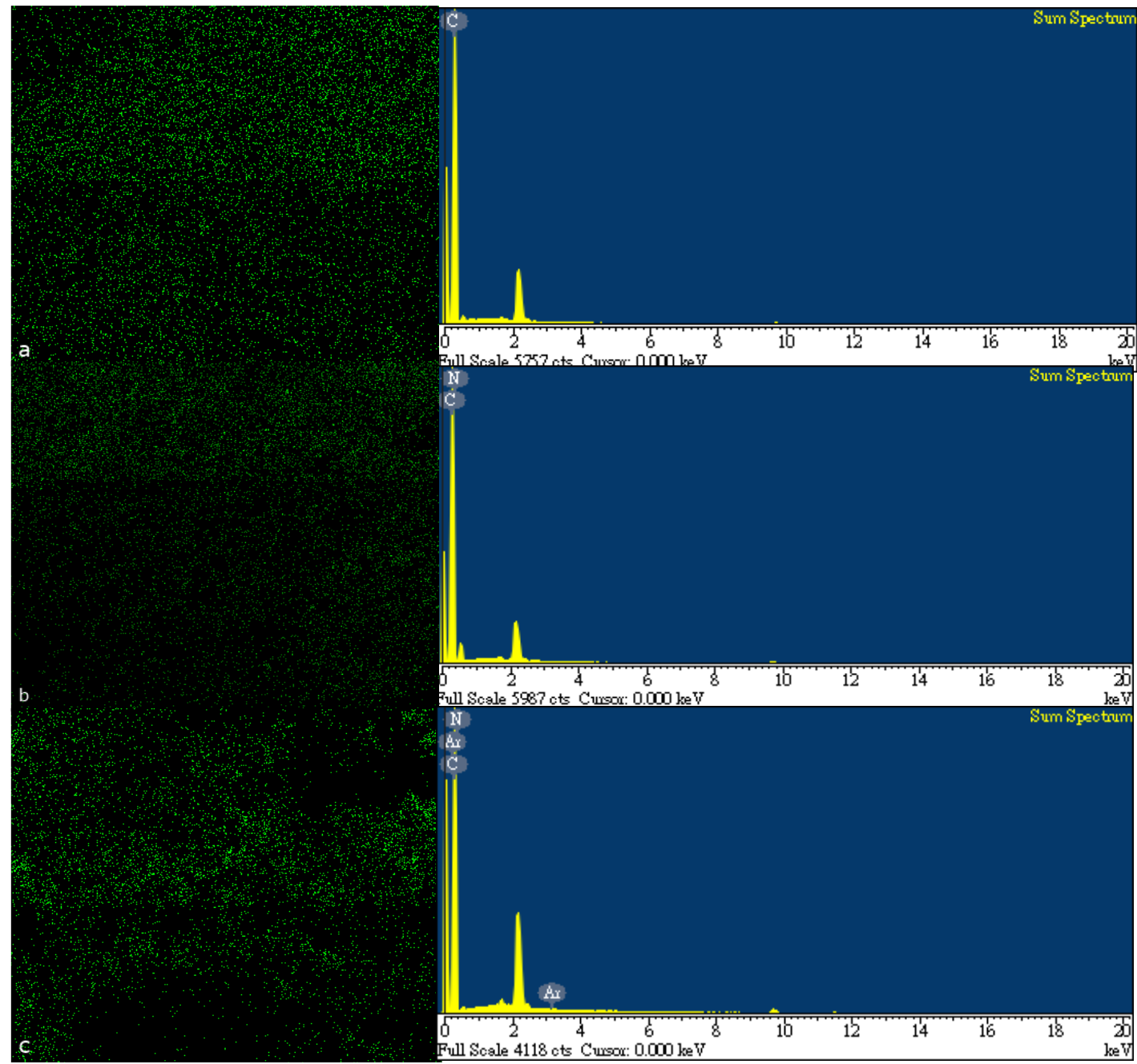

Fig. 4. Composition of carbon in the Styrofoam before treatment and its distribution of sample after treatment based on the EDX data. (a) Composition of carbon before treatment of PSF waste. (b) Composition of carbon after treatment of PSF waste using nitrogen as the carrier gas. (c) Distribution of carbon after treatment of PSF waste with argon gas.

a peak at $1633 \mathrm{~cm}^{-1}$. Interestingly, $1633 \mathrm{~cm}^{-1}$ and $3440 \mathrm{~cm}^{-1}$ wavenumbers were not detected during the analysis because of the elimination of chemical compounds after treatment using nitrogen plasma. Wavenumbers of $500-1600 \mathrm{~cm}^{-1}$ confirm $\mathrm{C}-\mathrm{H}$ and $\mathrm{C}-\mathrm{C}$ bonds (Singh et al., 2015; Ismail et $a l ., 2017)$. In this study, peaks in the range $500-1600 \mathrm{~cm}^{-1}$ were detected in the final residue, which were $\mathrm{C}-\mathrm{H}$ bonds and $\mathrm{C}-\mathrm{C}$ bonds, confirming the transformation of carbon to $\mathrm{H}_{2}$ and $\mathrm{CH}_{4}$

Fig. 6 compares the XRD analysis of the PSF waste before treatment and after treatment with the different carrier gases. Before treatment, the analysis showed a peak in the sample of $2 \theta$ at $10^{\circ}$ and $20^{\circ}$. The highest intensity peaks appeared in the final residue. Interestingly, the $2 \theta$ peak was not detected in the final residue after treatment using nitrogen plasma because of low intensity at $10^{\circ}$ and $25^{\circ}$, thus confirming the transformation of PSF waste due to carbon degradation. Liu et al. (2010) confirmed that diffraction peaks of $2 \theta$, ranging from $15-30^{\circ}$, explain amorphous carbon structures. In this study, the detection of peaks from $10^{\circ}$ and $20^{\circ}$ prior to treatment confirmed the amorphous carbon structure of the
PSF waste. Thus, gases can be possibly produced from the PSF waste because of the transformation of carbon.

\section{Effects of Microwave Power and Carrier Gases on the Generation of $\mathrm{CH}_{4}$ and $\mathrm{H}_{2}$}

Table 5 compares the results of $\mathrm{H}_{2}$ and $\mathrm{CH}_{4}$ after treatment with different microwave power settings and carrier gases in an atmospheric-pressure microwave plasma reactor. The highest concentrations were $\mathrm{CH}_{4}$ and $\mathrm{H}_{2}$ at $188 \mathrm{ppm}$ and $4739 \mathrm{ppm}$, respectively, in $5 \mathrm{~min}$, with $1200 \mathrm{~W}$ of microwave power and using nitrogen as the carrier gas. In this study, $1200 \mathrm{~W}$ of microwave power had a significant impact on greater generation of the gases. At $2 \mathrm{~min}, 2659 \mathrm{ppm}$ of $\mathrm{H}_{2}$ and $85 \mathrm{ppm}$ of $\mathrm{CH}_{4}$ were obtained with nitrogen plasma. This was a significant difference from plasma treatment with argon gas, for which the concentrations of $\mathrm{CH}_{4}$ and $\mathrm{H}_{2}$ were $7 \mathrm{ppm}$ and 1114 ppm, respectively. The highest concentrations using argon plasma can be obtained at $188 \mathrm{ppm}$ of $\mathrm{CH}_{4}$ and $4739 \mathrm{ppm}$ of $\mathrm{H}_{2}$.

Figs. 5(a) and 5(b) provide concentrations of $\mathrm{H}_{2}$ and $\mathrm{CH}_{4}$ in the final residue with different carrier gases and microwave 

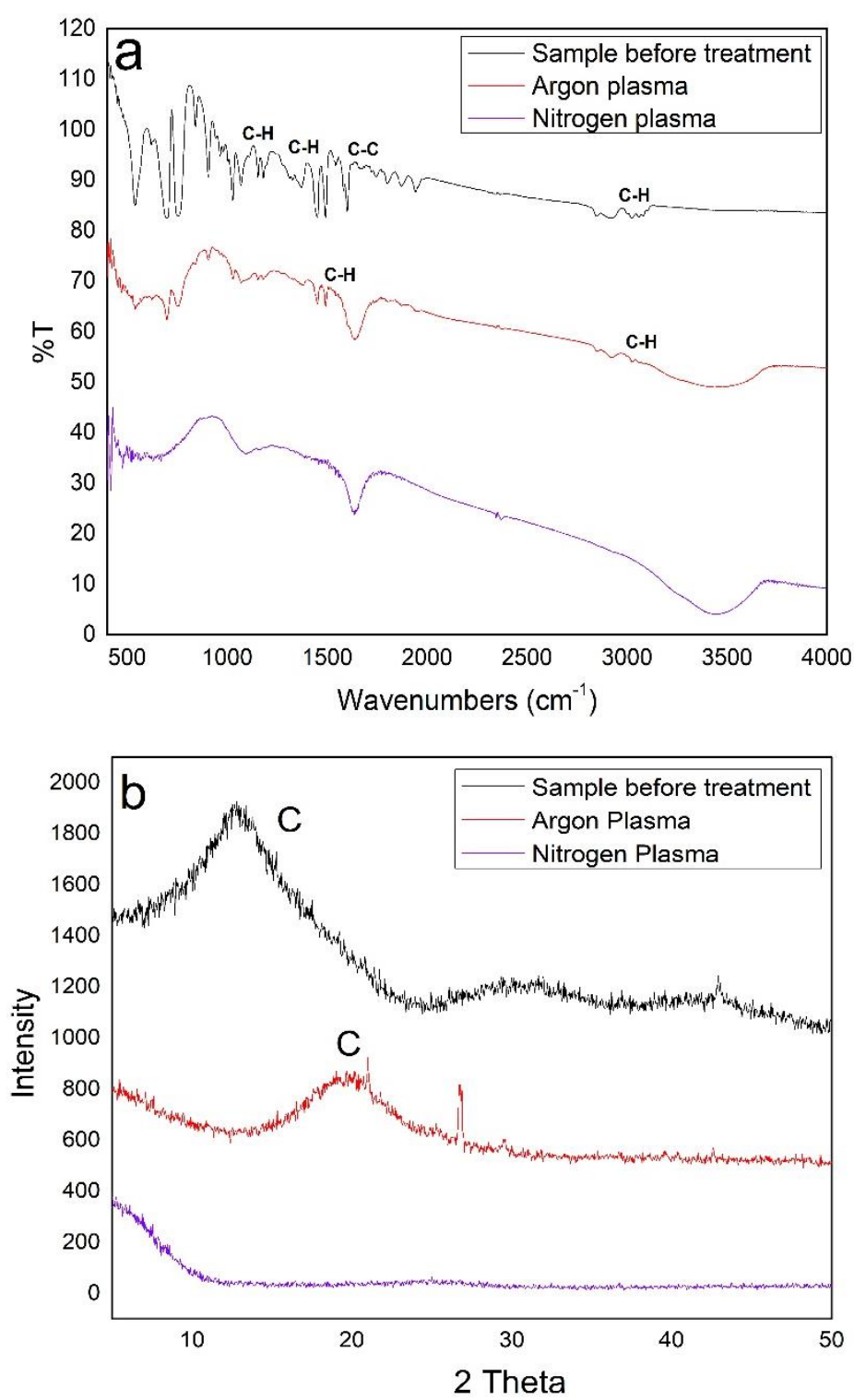

Fig. 5. Characterization of final residue (a) FTIR test of PSF waste before and after treatment. (b) XRD test of PSF waste before and after treatment.

Table 4. Spectrum analysis of PSF on the FTIR analysis.

\begin{tabular}{lll}
\hline Assignments & Wavenumbers $\left(\mathrm{cm}^{-1}\right)$ & Vibration Types \\
\hline C-H & $3001-3082$ & Stretching \\
C-H & $2910-2928$ & Stretching \\
C-C & 1601 & Stretching \\
C-H & 1493 & Stretching \\
C-H & 1028 & Bending \\
\hline
\end{tabular}

power settings. In the plasma treatment, the final concentrations of $\mathrm{H}_{2}$ were $3500-5000 \mathrm{ppm}$. Furthermore, the final concentration of $\mathrm{CH}_{4}$ was less than $500 \mathrm{ppm}$ with treatment using the selected parameters (nitrogen gas, $800 \mathrm{~W}$ and $1200 \mathrm{~W}$ ). With the use of argon as the carrier gas, the final concentrations of $\mathrm{H}_{2}$ ranged from approximately $700 \mathrm{ppm}$ to almost 1200 ppm, while the result for $\mathrm{CH}_{4}$ were less than $100 \mathrm{ppm}$ using the selected parameters $(800 \mathrm{~W}$ and $1200 \mathrm{~W})$.
From this analysis, it can be inferred that higher microwave power and nitrogen gas play an important role in generating gases due to high thermal plasma enthalpy (Mountouris et al., 2006; An'shakov et al., 2007). The conversion of carbon to gases during plasma pyrolysis occurs because of the reaction of molecules (Maczka et al., 2013). During plasma treatment, a higher temperature plays an important role in degrading the components of the residue to simple molecules 

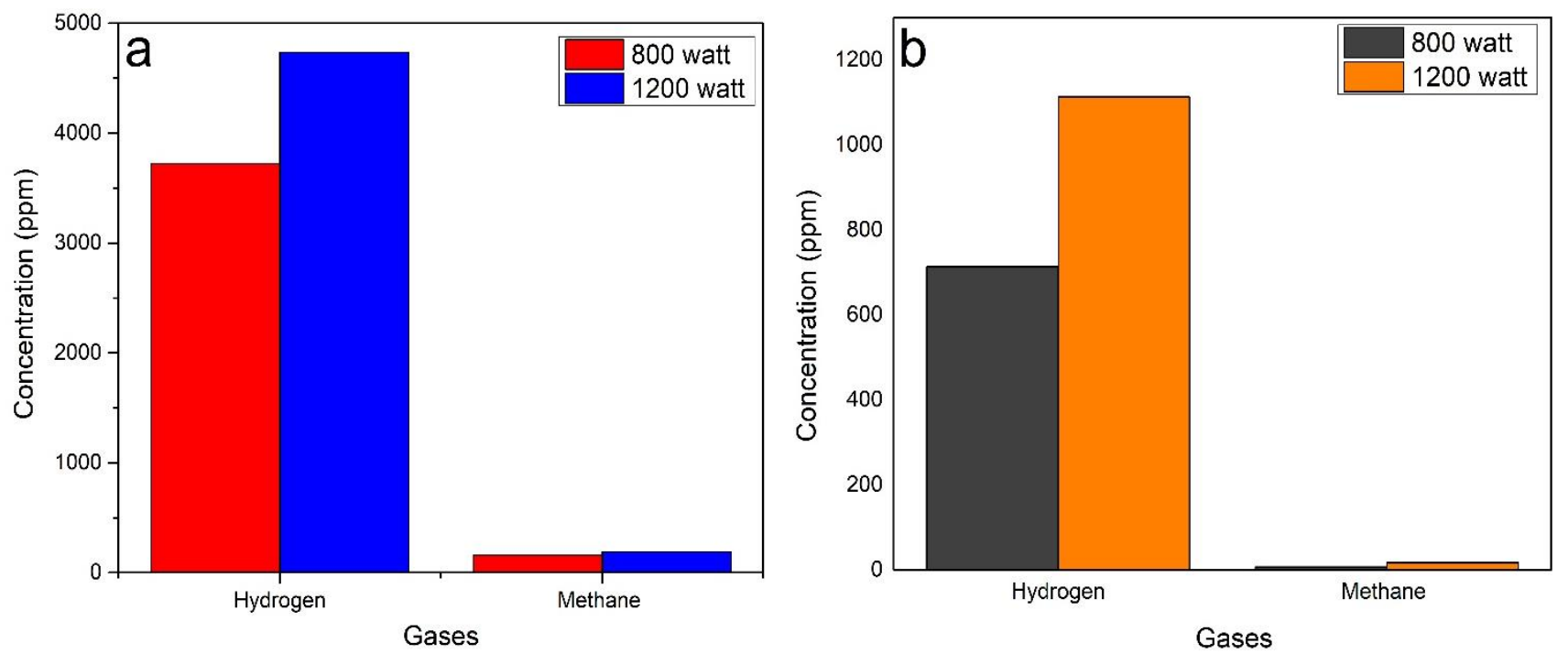

Fig. 6. Total concentration of $\mathrm{CH}_{4}$ and $\mathrm{H}_{2}$ (a) treatment with nitrogen gas. (b) Treatment with argon gas.

Table 5. Analysis of hydrogen and methane on different microwave power.

\begin{tabular}{|c|c|c|c|c|c|}
\hline \multirow{2}{*}{ Microwave power (watt) } & \multirow{2}{*}{ Time (s) } & \multicolumn{2}{|c|}{ Nitrogen Plasma } & \multicolumn{2}{|c|}{ Argon Plasma } \\
\hline & & $\mathrm{CH}_{4}(\mathrm{ppm})$ & $\mathrm{H}_{2}(\mathrm{ppm})$ & $\mathrm{CH}_{4}(\mathrm{ppm})$ & $\mathrm{H}_{2}(\mathrm{ppm})$ \\
\hline \multirow[t]{11}{*}{800 watt } & 0 & 0 & 0 & 0 & 0 \\
\hline & 30 & 7 & 174 & 2 & 87 \\
\hline & 60 & 5 & 179 & 0.4 & 54 \\
\hline & 90 & 6 & 121 & 0.7 & 84 \\
\hline & 120 & 6 & 274 & 1.2 & 64 \\
\hline & 150 & 37 & 765 & 0.5 & 80 \\
\hline & 180 & 85 & 1711 & 0.2 & 99 \\
\hline & 210 & 101 & 338 & 0.2 & 42 \\
\hline & 240 & 3 & 162 & 0.1 & 42 \\
\hline & 270 & - & - & 1.8 & 72 \\
\hline & 300 & - & - & 0.2 & 90 \\
\hline Total & & 250 & 3724 & 7 & 714 \\
\hline \multirow[t]{11}{*}{1200 watt } & 0 & 0 & 0 & 0 & 0 \\
\hline & 30 & 15 & 103 & 3 & 149 \\
\hline & 60 & 35 & 264 & 2.2 & 114 \\
\hline & 90 & 25 & 929 & 0.6 & 136 \\
\hline & 120 & 85 & 2659 & 1.2 & 91 \\
\hline & 150 & 13 & 605 & 1 & 81 \\
\hline & 180 & 7.4 & 90 & 2 & 106 \\
\hline & 210 & 5 & 42 & 1.8 & 104 \\
\hline & 240 & 3 & 47 & 2 & 101 \\
\hline & 270 & - & - & 1.9 & 99 \\
\hline & 300 & - & - & 1.6 & 133 \\
\hline Total & & 188 & 4739 & 17.3 & 1114 \\
\hline
\end{tabular}

(Dave and Joshi, 2010). Specifically, the collision of molecules and reactive species occurs in the plasma, causing the degradation of complex molecules to simpler molecules. Furthermore, high ionization of atoms from energetic electrons colliding with the material rapidly decomposed the material into gaseous products that release radicals such as $\mathrm{H}, \mathrm{O}$, and $\mathrm{N}$ (Mackza et al., 2013). Thus, $\mathrm{CH}_{4}$ and $\mathrm{H}_{2}$ gases can be formed directly in the plasma pyrolysis process, for which the mechanism described in Fig. 7, where it is shown that electrons collide with atoms from the PSF waste, and then carbon is converted into gases. The final residues after treatment of PSF waste are both solid and liquid*9. Approximately $0.002 \mathrm{~g}$ of solids were obtained. However, the amount of liquid was difficult to measure due to its limited amount. Fig. S1 shows the details for final PSF waste after treatment. The information of the mass balance was shown in Fig. S2. In this study, $0.1 \mathrm{~g}, 0.2 \mathrm{~g}$ and $0.3 \mathrm{~g}$ of PSF waste were the input amounts, respectively. Outputs were 


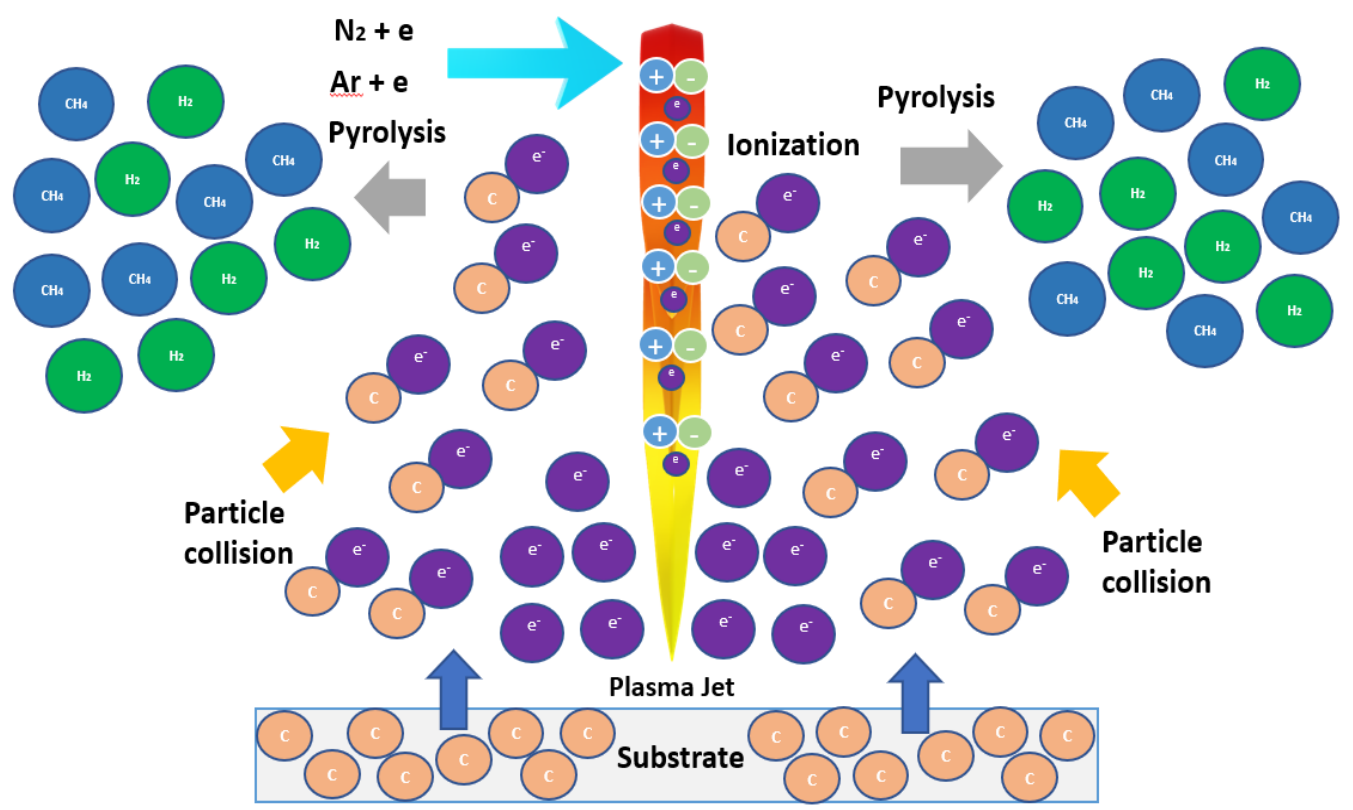

Fig. 7. Mechanism of gas production during treatment in an atmospheric-pressure microwave plasma reactor.

hydrogen and methane gases, and black carbon residue. Dave and Joshi (2010) confirmed that plasma gasification generates $65 \%$ hydrogen. Maczka et al. (2013) stated that a common gasification reaction can be associated with the pattern:

Polyethylene $\left(\mathrm{CH}_{2}-\mathrm{CH}_{2}\right)+$ Plasma $+\mathrm{H}_{2} \mathrm{O} \rightarrow \mathrm{X}\left(\mathrm{CH}_{4}\right)+$ $z(\mathrm{CO})+$ Radicals $\rightarrow n(\mathrm{CO})+m\left(\mathrm{H}_{2}\right)$

According to Mountouris et al. (2005) the common gasification reaction known as an equilibrium reaction, that can be described by an ultimate analysis $\left(\mathrm{CH}_{x} \mathrm{O}_{y}\right)$, as follows:

$$
\begin{aligned}
& \mathrm{CH}_{x} \mathrm{O}+w \mathrm{H}_{2} \mathrm{O}+\mathrm{mO}_{2}+3.76 \mathrm{mN}_{2} \rightarrow a \mathrm{H}_{2}+b \mathrm{CO}+c \mathrm{CO}_{2} \\
& +d \mathrm{H}_{2} \mathrm{O}+e \mathrm{CH}_{4}+f \mathrm{~N}_{2}+g \mathrm{C}
\end{aligned}
$$

Mattox (2010) stated that electrons accelerate rapidly through an electric field from the plasma source, where ionizing collisions are responsible for the loss of atoms from the target, and the electrons from plasma bombarded the surface area of the sample, thus transforming the final residue. Furthermore, $\mathrm{H}$ and $\mathrm{CH}_{4}$ gases are obtained as side products.

\section{Effect of Different PSF Amounts to Generate $\mathrm{CH}_{4}$ and $\mathrm{H}_{2}$}

Fig. 8 shows the different sample weights used for the $\mathrm{CH}_{4}$ and $\mathrm{H}_{2}$ production using nitrogen as the carrier gas. The highest $\mathrm{H}_{2}$ gas concentration was 19,657 ppm obtained from $0.2 \mathrm{~g}$ sample (Table 6). More striking was the highest $\mathrm{CH}_{4}$ concentration of $440 \mathrm{ppm}$ with same amount of PSF waste (Table 6). The lowest concentrations of $\mathrm{CH}_{4}$ and $\mathrm{H}_{2}$ were $170 \mathrm{ppm}$ and $5642 \mathrm{ppm}$, respectively, which were obtained with $0.1 \mathrm{~g}$ of sample material. When using higher amounts of PSF waste $(0.3 \mathrm{~g})$, a longer duration of pyrolysis should be used to obtain a better result. The higher microwave power improves the chemical reaction occurring during the plasma treatment, which results in higher $\mathrm{H}_{2}$ concentrations

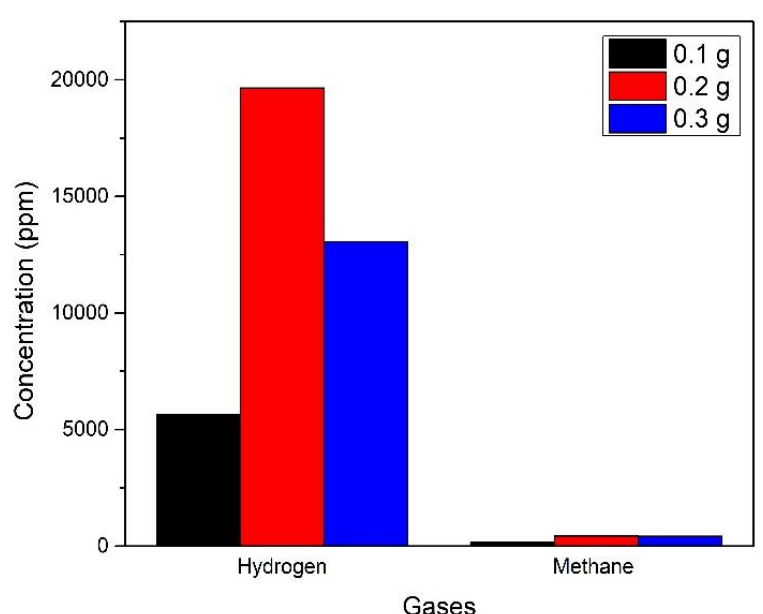

Fig. 8. Effect of sample weight on gas production rate of $\mathrm{CH}_{4}$ and $\mathrm{H}_{2}$.

due to the higher temperature (Dominguez et al., 2007; Dave and Joshi, 2010). In this study, the rapid high-temperature plasma pyrolysis can be obtained on the higher set-up of microwave power. Dave and Joshi (2010) stated that a higher plasma temperature plays an auxiliary role in the transformation of a material into simpler molecules. In this study, lower concentrations of $\mathrm{H}_{2}$ and $\mathrm{CH}_{4}$ were achieved because of a slower reaction of the argon plasma jet at lower temperature corresponds to the microwave power. $\mathrm{H}_{2}$ formation can be improved by increasing the pyrolysis temperature, causes dehydrogenation reaction of aromatic hydrocarbons and condensates associated with the pyrolysis temperature, dehydrogenation, and aromatic hydrocarbon (Zhao et al., 2012; Dominguez et al., 2017). A higher microwave power for plasma increases the temperature reaction, which was linked with the better results for $\mathrm{H}_{2}$ and $\mathrm{CH}_{4}$ found in this study. Thereby, higher concentrations of 
Table 6. $\mathrm{CH}_{4}$ and $\mathrm{H}_{2}$ gases concentration after treatment in an atmospheric-pressure microwave plasma reactor using nitrogen as the carrier gas.

\begin{tabular}{|c|c|c|c|c|c|c|c|}
\hline \multirow{2}{*}{ No } & \multirow{2}{*}{ Time (s) } & \multicolumn{3}{|c|}{ Hydrogen (ppm) } & \multicolumn{3}{|c|}{ Methane (ppm) } \\
\hline & & $0.1 \mathrm{~g}$ & $0.2 \mathrm{~g}$ & $0.3 \mathrm{~g}$ & $0.1 \mathrm{~g}$ & $0.2 \mathrm{~g}$ & $0.3 \mathrm{~g}$ \\
\hline 1 & 0 & 0 & 0 & 0 & 0 & 0 & 0 \\
\hline 2 & 30 & 105 & 510 & 633 & 6 & 21 & 39 \\
\hline 3 & 60 & 338 & 209 & 610 & 9 & 8 & 92 \\
\hline 4 & 90 & 710 & 514 & 511 & 16 & 6 & 3 \\
\hline 5 & 120 & 2099 & 132 & 514 & 61 & 12 & 14 \\
\hline 6 & 150 & 1926 & 3238 & 1009 & 64 & 89 & 27 \\
\hline 7 & 180 & 213 & 2303 & 975 & 6 & 68 & 29 \\
\hline 8 & 210 & 167 & 2666 & 1809 & 5 & 48 & 53 \\
\hline 9 & 240 & 83 & 159 & 5800 & 3 & 30 & 135 \\
\hline 10 & 270 & - & 534 & 569 & - & 50 & 12 \\
\hline 11 & 300 & - & 4434 & 287 & - & 58 & 8 \\
\hline 12 & 330 & - & 3100 & 81 & - & 35 & 11 \\
\hline 13 & 360 & - & 1858 & 263 & - & 15 & 12 \\
\hline Tota & & 5642 & 19,657 & 13,061 & 170 & 440 & 435 \\
\hline
\end{tabular}

$\mathrm{H}_{2}$ can be obtained when the microwave power is kept constant at a higher power. In this study, a 5 min plasma reaction increased the temperature from $600^{\circ} \mathrm{C}$ to $700^{\circ} \mathrm{C}$.

Carbon and other volatile materials in PSF waste are converted to $\mathrm{CO}, \mathrm{H}_{2}$ and $\mathrm{C}_{x} \mathrm{H}_{y}$ through chemical reactions (Ruj and Chang, 2012). Tang et al. (2003) stated that tar can be degraded effectively into $\mathrm{CO}$ and $\mathrm{H}_{2}$ as the final products, thus confirming the significant production of $\mathrm{H}_{2}$ because of the higher feed rate in a plasma system. This finding confirmed that PSF waste leads to good gas production results after 4 min of pyrolysis. Carbon decompose because of an oxidation process that generates $\mathrm{CH}_{4}$ and $\mathrm{H}_{2}$ (Fabry et al., 2013; Maczka et al., 2013). $\mathrm{H}_{2}$ and $\mathrm{CH}_{4}$ gases are the byproduct bond dissociation and endothermic reactions where the exothermic reaction releases energy from the heat at plasma jet discharge (Nema and Ganeshprasad, 2002). Thus, these gases can be generated from plasma pyrolysis.

In this investigation, $\mathrm{H}_{2}$, the main product of plasma pyrolysis, was described as the main primary gas obtained during the plasma treatment. The pyrolysis of gas plays an important role in converting solid waste to syngas, namely, $\mathrm{H}_{2}$ and $\mathrm{CH}_{4}$, which can potentially be substituted for fossil fuels and as alternative sources of energy (Gomez et al., 2009) and may be potentially used into the electricity application (Maczka et al., 2013). $\mathrm{H}_{2}$ and $\mathrm{CH}_{4}$ can be obtained from the plasma pyrolysis of PSF waste, owing to carbon conversion in an atmospheric-pressure microwave plasma reactor. The pyrolysis of syngas depends on the parameters used in plasma treatment and amount of PSF waste. These results may be considered as preliminary information to give the information on the conversion of PSF waste to $\mathrm{CH}_{4}$ and $\mathrm{H}_{2}$.

\section{CONCLUSION}

Employing an atmospheric-pressure microwave plasma reactor, and argon and nitrogen as carrier gases, we produced syngas on a pilot scale by converting carbon into $\mathrm{CH}_{4}$ and $\mathrm{H}_{2}$ during the treatment of PSF waste. Using nitrogen instead of argon as the carrier gas and increasing the microwave power proved to be the optimal method, achieving $\mathrm{CH}_{4}$ and $\mathrm{H}_{2}$ concentrations of 19,657 ppm and $440 \mathrm{ppm}$, respectively, for $0.2 \mathrm{~g}$ of PSF. The SEM-EDX and XRD results for the final residue confirmed the structural transformation of the PSF and a decrease in carbon content. Future research should focus on maximizing the concentration of the generated syngas, which depends partially on the quantity of the waste. Mixing the carrier gas with $\mathrm{H}_{2} \mathrm{O}$, increasing the duration of the pyrolysis, and performing a cost analysis are also potential steps. Furthermore, investigating the particulate matter (PM) and aerosols released by the atmospheric-pressure microwave plasma reactor will enable us to control pollutive emissions associated with this technology.

\section{ACKNOWLEDGEMENT}

This research was financially supported by Ministry of Science and Technology (MOST), Taiwan, with a grant number of 107-2221-E-033-005. We thank the Department of Environmental Engineering, Chung Yuan Christian University, where the study was undertaken.

\section{DISCLAIMER}

Authors declare no competing of financial interest in this research. Facts and opinions in articles are solely the primary results of authors.

\section{SUPPLEMENTARY MATERIAL}

Supplementary data associated with this article can be found in the online version at https://doi.org/10.4209/aaqr.2 020.05.0252

\section{REFERENCES}

Allen, R.J., Jarvis, D., Sayer, S. and Mills, C. (2012). Entanglement of grey seals Halichoerus grypus at a haul out site in Cornwall, UK. Mar. Pollut. Bull. 64: 2815- 
2819. https://doi.org/10.1016/j.marpolbul.2012.09.005

An'shakov, A.S., Faleev, V.A., Danilenko, A.A., Urbakh, E.K. and Urbakh, A.E. (2007). Investigation of plasma gasification of carbonaceous technologies wastes. Thermophys. Aeromech. 14: 607-616. https://doi.org/10. 1134/S0869864307040105

Benedikt, J. (2010). Plasma-chemical reactions: Low pressure acetylene plasma. J. Appl. Phys. 43: 043001. https://doi.org/10.1088/0022-3727/43/4/043001

Byun, Y., Cho, M., Chung, J.W., Namkung, W., Lee, H.D., Jang, S.D., Kim, Y.S., Lee, J.H. and Hwang, S.M. (2011). Hydrogen recovery from the thermal plasma gasification of solid waste. J. Hazard. Mater. 190: 317-323. https://doi.org/10.1016/j.jhazmat.2011.03.052

Chen, L.C., Kuo., P.H, Lee, T.C. and Liu, C.H. (2018). Snow lines on shorelines: Solving Styrofoam buoy marine debris from oyster culture in Taiwan. Ocean Coastal Manage. 165: 346-355. https://doi.org/10.1016/ j.ocecoaman.2018.09.005

Choi, D.H., Chun, S.M., Ma, S.H. and Hong, Y.C. (2016). Production of hydrogen-rich syngas from methane reforming by steam microwave plasma. J. Ind. Eng. Chem. 34: 286-291. https://doi.org/10.1016/j.jiec.2015.11.019

Choi, K.I., Lee, S.H., Lee, D.H. and Osako. M. (2008). Fundamental characteristics of input waste of small MSW incinerators in Korea. Waste Manage. 28: 2293-2300. https://doi.org/10.1016/j.wasman.2007.10.008

Chu, J.P., Chen, Y.T., Mahalingam, T., Tzeng, C.C. and Cheng, T.W. (2006). Plasma vitrification and re-use of non-combustible fiber reinforced plastic, gill net and waste glass. J. Hazard Mater. 138: 628-632. https://doi.org/10.1016/j.jhazmat.2006.05.107

Codina-Garcia, M., Militao, T., Moreno, J. and GonzalezSolis, J. (2013). Plastic debris in Mediterranean seabirds. Mar. Pollut. Bull. 77: 220-226. https://doi.org/10.1016/j. marpolbul.2013.10.002

Dave, P. N. and Joshi, A.K. (2010). Plasma pyrolysis and gasification of plastics waste - A review. J. Sci. Ind. Res. 69: $177-179$.

Deng, C.X., Lu, S.H., Bao, T., Liu, X.W. and Yu, Z.M. (2019). Decomposition of carbon disulphide using dielectric barrier discharge plasma coupled with limonite and siderite supported bismuth vanadate catalysts. Aerosol Air Qual. Res. 19: 2352-2365. https://doi.org/10. 4209/aaqr.2019.08.0373

Dominguez, A., Menendez, J.A., Fernandez, Y., Pis, J.J., Nabais, J.M.V., Carrott, P.J.M. and Carrott. M.M.L.R. (2007). Conventional and microwave induced pyrolysis of coffee hulls for the production of a hydrogen rich fuel gas. J. Anal. Appl. Pyrolysis 79: 128-135. https://doi.org/ 10.1016/j.jaap.2006.08.003

European Commission (2006). Integrated pollution prevention and control-Reference document on the best available techniques for waste incineration. https://eippcb.jrc.ec.eu ropa.eu/sites/default/files/2020-01/sa_bref_0505.pdf

Fabry, F., Rehmet, C., Rohani, V. and Fulcheri, L. (2013). Waste gasification by thermal plasma: A review. Waste Biomass Valorization 4: 421-439. https://doi.org/10.1007/ s12649-013-9201-7
Farrelly, T.A. and Shaw, I.C. (2017). Polystyrene as hazardous household waste. Household hazardous waste management, Mmereki, D. (Ed.), IntechOpen, https://doi.org/10.5772/ 65865

Fujieda S, Sasaki K (2005) Stranded debris of foamed plastics on the coast of Eta Island and Kurahashi Island in Hiroshima Bay. Nippon Suisan Gakk. 71: 755-761. https://doi.org/10.2331/suisan.71.755

Gomez, E., Rani, D.A., Cheeseman, C.R., Deegan, D., Wise, M. and Boccaccini, A.R. (2009). Thermal plasma technology for the treatment of wastes: A critical review. J. Hazard Mater. 161: 614-626. https://doi.org/10.1016/j. jhazmat.2008.04.017

Heberlein, J. and Murphy, A.B. (2008). Thermal plasma waste treatment. J. Phys. D: Appl. Phys. 41: 053001. https://doi.org/10.1088/0022-3727/41/5/053001

Holland, E.R., Mallory, M.L. and Shutler, D. (2016). Plastics and other anthropogenic debris in freshwater birds from Canada. Sci. Total Environ. 571: 251-258. https://doi.org/10.1016/j.scitotenv.2016.07.158

Hong, S., Lee, J., Kang, D., Choi, H.W. and Ko, S.H. (2014). Quantities, composition, and sources of beach debris in Korea from the results of nationwide monitoring. Mar. Pollut. Bull. 84: 27-34. https://doi.org/10.1016/j.marpolb ul.2014.05.051

Huang, H., Tang, L. and Wu, Z. (2003). Characterization of gaseous and solid product from thermal plasma pyrolysis of waste rubber. Environ. Sci. Technol. 37: 4463-4467. https://doi.org/10.1021/es034193c

Huang, X.Y., Cheng, D.G. Chen, F.Q. and Zhan, X.L. (2016). Reaction pathways of hemicellulose and mechanism of biomass pyrolysis in hydrogen plasma: A density functional theory study. Renewable Energy 96: 490-497. https://doi.org/10.1016/j.renene.2016.04.080

Ismail, R.A., Almashhadani, N.J. and Sadik, R.H. (2017). Preparation and properties of polystyrene incorporated with gold and silver nanoparticles for optoelectronic applications. Appl. Nanosci. 7: 109-116. https://doi.org/1 0.1007/s13204-017-0550-6

Khani, M.R., Guy, E.D., Khosravi, A. and Shokri, B. (2014). Effect of microwave plasma torch on the pyrolysis fuel oil in the presence of methane and ethane to increase hydrogen production. Int. J. Hydrogen Energy 39: 1881218819. https://doi.org/10.1016/j.ijhydene.2014.09.066

Laglbauer, B.J.L., Franco-Santos, R.M., Andreu-Cazenave, M., Brunelli, L., Papadatou, M., Palatinus, A., Grego, M. and Deprez, T. (2014). Macrodebris and microplastics from beaches in Slovenia. Mar. Pollut. Bull. 89: 356-366. https://doi.org/10.1016/j.marpolbul.2014.09.036

Lee, J.L., Hong, J., Hong, S.H., Shim, W.J. and Eo, S. (2017). Characteristics of meso-sized plastic marine debris on 20 beaches in Korea. Mar. Pollut. Bull. 123: 9296. https://doi.org/10.1016/j.marpolbul.2017.09.020

Lee, J.M., Hong, S.W., Jang, Y.C., Lee, M.J., Kang, D.S. and Shim, W.J. (2015). Finding solutions for the Styrofoam buoy debris problem through participatory workshops. Mar. Policy 51: 182-189. https://doi.org/10.1 016/j.marpol.2014.08.008

Liang, K. and Zhang, Q. (2010). Study on the organizational 
structured problem solving on total quality management. Int. J. Bus. Manage. 5: 178-183. https://doi.org/10.5539/ ijbm.v5n10p178

Liu, T.K., Wang, M.W. and Chen, P. (2013). Influence of waste management policy on the characteristics of beach litter in Kaohsiung, Taiwan. Mar. Pollut. Bull. 72: 99106. https://doi.org/10.1016/j.marpolbul.2013.04.015

Liu, X.Y., Huang, M., Ma, H.L., Zhang, Z.Q., Gao, J.M., Zhu, Y.L., Han, X.J. and Guo, X.Y. (2010). Preparation of a carbon-based solid acid catalyst by sulfonating activated carbon in a chemical reduction process. Molecules 15: 7188-7196. https://doi.org/10.3390/molec ules 15107188

Maczka, T., Sliwka, E. and Wnukowaski, M. (2013). Plasma gasification of waste plastics. J. Eco. Eng. 14: 33-39. https://doi.org/10.5604/2081139X.1031534

Materazzi, M., Lattieri, P., Mazzei, P.L., Taylor, R. and Chapman, C. (2015). Reforming of tars and organic sulphur compounds in a plasma-assisted process for waste gasification. Fuel Process. Technol. 137: 259-268. https://doi.org/10.1016/j.fuproc.2015.03.007

Mattox, D.M. (2010). Chapter 5 - The low pressure plasma processing environment. In D.M. Mattox (Ed.), Handbook of Physical Vapor Deposition (PVD) Processing (Second Edition) (pp. 157-193). William Andrew Publishing. https://doi.org/10.1016/B978-0-8155-2037-5.00005-8

Mazzoni, L. and Janajreh, I. (2017). Plasma gasification of municipal solid waste with variable content of plastic solid waste for enhanced energy recovery. Int. J. Hydrogen Energy 42: 19446-19457. https://doi.org/10.1 016/j.ijhydene.2017.06.069

Mountouris, A., Voustsas, E. and Tassios, T. (2005). Solid waste plasma gasification: Equilibrium model development and exergy analysis. Energy Convers. Manage. 47, 17231737. https://doi.org/10.1016/j.enconman.2005.10.015

Nema, S.K. and Ganeshprasad, K.S. (2002). Plasma pyrolysis of medical waste. Curr. Sci. 83. 271-278. http://www.jstor.org/stable/24106885

Pomeroy, R.S. and Guieb, R.R. (2006). Fishery comanagement: A practical handbook. International Development Research Centre.

Provencher, J.F., Gaston, A.J., Mallory, M.L., O’Hara, P.D. and Gilchrist, H.G. (2010). Ingested plastic in a diving seabird, the thick-billed murre (Uria lomvia), in the eastern Canadian Arctic. Mar. Pollut. Bull. 60: 14061411. https://doi.org/10.1016/j.marpolbul.2010.05.017

Ruj, B. and Chang, J.S. (2012). Combustible gases from thermal plasma treatment of plastic waste with special reference to mobile phone waste. Int. J. Plast. Technol. 16: 182-193. https://doi.org/10.1007/s12588-012-9041-5

Safa, S. and Soucy, G. (2014). Liquid and solution treatment by thermal plasma: A review. Int. J. Environ. Sci. Technol. 11: 1165-1188. https://doi.org/10.1007/s13762-013-0356-3

Sanito, R.C., You, S.J., Chang, G.M. and Wang, Y.F. (2020). Effect of shell powder on removal of metals and volatile organic compounds (VOCs) from resin in an atmospheric-pressure microwave plasma reactor. $J$. Hazard. Mater. 394: 122558. https://doi.org/10.1016/j.jh azmat.2020.122558
Shie, J.L., Chen, L.X., Lin, K.L. and Chang, C.Y. (2014). Plasmatron gasification of biomass lignocellulosic waste materials derived from municipal solid waste. Energy 66: 82-89. https://doi.org/10.1016/j.energy.2013.12.042

Singh, S., Singh, P.K. and Mahalingam, H. (2015). An effective and low-cost $\mathrm{TiO}_{2}$ /polystyrene floating photocatalyst for environmental remediation. Int. J. Environ. Res. 9: 535-544.

Song, J.B., Yuan, Q.P., Liu, X.S., Wang, D., Fu, F. and Yang, W.B. (2015). Combination of nitrogen plasma modification and waterborne polyurethane treatment of carbon fiber paper used for electric heating of wood floors. BioResources 10: 5820-5829.

Tanaka, K., Takada, H., Yamashita, R., Mizukawa, K., Fukuwaka, M.A. and Watanuki, Y. (2013). Accumulation of plastic-derived chemicals in tissues of seabirds ingesting marine plastics. Mar. Pollut. Bull. 69: 219-222. https://doi.org/10.1016/j.marpolbul.2012.12.010

Tang, L., Huang, H., Zhao, Z.L., Wu, C.Z. and Chen, Y. (2003). Pyrolysis of polypropylene in a nitrogen plasma reactor. Ind. Eng. Chem. Res. 42: 1145-1150. https://doi.org/10.1021/ie020469y

UNEP (2013). Green economy and trade, trends, challenges and opportunities. http://www.unep.org/greeneconomy/G reenEconomyandTrade

Vince, J. and Hardesty, B.D. (2018). Governance solutions to the tragedy of the commons that marine plastics have become. Front. Mar. Sci. 5: 1-10. https://doi.org/10.3389/ fmars.2018.00214

Walther, B.A., Kunz, A. and Hu, C.S. (2018). Type and quantity of coastal debris pollution in Taiwan: A 12-year nationwide assessment using citizen science data. Mar Pollut Bull. 35: 862-872. https://doi.org/10.1016/j.marpo lbul.2018.08.025

Wang, Q., Miyake, Y., Tokomura, M., Amagai, T., Horii, Y., Nojiri, K. and Ohtsuka, N. (2018). Effects of characteristics of waste incinerator on emission rate of halogenated polycyclic aromatic hydrocarbon into environments. Sci. Total Environ. 625: 633-639. https://doi.org/10.1016/j.scitotenv.2017.12.323

Wang, Y.F., Tsai, C.H., Chang, W.Y. and Kuo, Y.M. (2010). Methane steam reforming for producing hydrogen in an atmospheric-pressure microwave plasma reactor. Int. J. Hydrogen Energy 35: 135-140. https://doi.org/10.1 016/j.ijhydene.2009.10.088

Wu, S.L., Kuo, J.H. and Wey, M.Y. (2019). Hydrogen promotion by $\mathrm{Co} / \mathrm{SiO}_{2} @ \mathrm{HZSM}-5$ core-shell catalyst for syngas from plastic waste gasification: The combination of functional materials. Int. J. Hydrogen Energy 44: 1348013489. https://doi.org/10.1016/j.ijhydene.2019.04.031

Xu, P.J., Tao, B., Li, N., Qi, L., Ren, Y., Zhou, Z.G., Zhang, L.F., Liu, A. and Huang, Y. (2013). Levels, profiles, and source identification of PCDD/Fs in farmland soils of Guiyu, China. Chemosphere 91: 824-831. https://doi.org/ 10.1016/j.chemosphere.2013.01.068

Yang, L., G.R. Liu, Q.Q. Zhu, M.H. and Zheng. (2019). Small-scale waste incinerators in rural China: Potential risks of dioxin and polychlorinated naphthalene emissions. Emerging Contam. 5: 31-34. https://doi.org/10.1016/j.em con.2019.01.001 
Yang, M. and Shibasaki, Y. (1998). Mechanism of thermal degradation of polystyrene, polymethacrylonitrile and their copolymers on flash pyrolysis. J. Polym. Sci., Part A 36: 2315-2330. https://doi.org/10.1002/(SICI)1099-0518(1 9980930)36:13\%3C2315::AID-POLA19\%3E3.0.CO;2-D

Zhao, X., Wang, M., Liu, H., LI, L., Ma, C. and Song, Z. (2012). A microwave reactor for characterization of pyrolyzed biomass. Bioresource Technol. 104: 673-678. https://doi.org/10.1016/j.biortech.2011.09.137

Zhou, X.Y., Cao, Y.Z., Yang, K., Yu, P.J., Chen, W.M., Wang, S.Q. and Chen, M.Z. (2020). Clean plasma modification for recycling waste plastic bags: From improving interfacial adhesion with wood towards fabricating formaldehyde-free plywood. J. Cleaner Prod. 269: 1221966. https://doi.org/10.1016/j.jclepro.2020.122 196

Received for review, May 22, 2020

Revised, July 14, 2020

Accepted, July 14, 2020 